\title{
RELATO DE EXPERIÊNCIA DE UM CURSO ONLINE SOBRE FUNGOS DESENVOLVIDO COM PROFESSORES SOB A PERSPECTIVA DE EDUCAÇÃO AMBIENTAL "FORA DA CAIXA"
}

\author{
Vanessa Aparecida Qualho ${ }^{1}$ \\ Valéria Ghisloti lared ${ }^{2}$
}

Resumo: O objetivo deste trabalho é relatar o desenvolvimento e análise de um curso online sobre fungos para professores da Educação Básica de Palotina (PR) sob a perspectiva da Educação Ambiental "fora da caixa", a qual descentraliza os elementos cognitivos durante a experiência. Para analisar os resultados, foi delimitado o corpus de análise: 1) questionário diagnóstico; 2) portfólio e 3) questionário avaliativo. Após a coleta de dados, foi realizada uma triangulação que apontou para a prevalência do método cartesiano e o desafio em se trabalhar com a perspectiva somaestética. Por fim, conclui-se sobre a importância de motivar outros estudos que preconizem pela multissensorialidade nas práticas em Educação Ambiental.

Palavras-chave: Educação da Atenção; Experiência Estética; Micologia

Abstract: The aim of this paper is to report the development and analysis of an online course on fungi for teachers of Secondary Education in Palotina (PR, Brazil) from the perspective of environmental education "out of the box", which decentralizes the cognitive elements during the experience. To analyze the results, the corpus of analysis was delimited: 1) diagnostic questionnaire; 2) portfolio and 3) evaluative questionnaire. After data collection, a triangulation was carried out which pointed to the prevalence of the Cartesian method and the challenge of working with the somaestetic perspective. It concludes about the importance of motivating other studies that advocate for multisensoriality in environmental education practices.

Keywords: Education of Attention; Aesthetic Experience; Mycology.

\footnotetext{
1 Universidade Federal do Paraná. E-mail: vanessaqualho@ufpr.br, Link para o Lattes: http://lattes.cnpq.br/2876458969593894

2 Universidade Federal do Paraná. E-mail: valeria.iared@ufpr.br, Link para o Lattes: http://lattes.cnpq.br/1273203310250467
} 


\section{Introdução}

Conforme a Constituição Brasileira de 1988 e a Política Nacional de Educação Ambiental, a Educação Ambiental deve estar presente de modo articulado em todas as modalidades e níveis de ensino (BRASIL, 1988; BRASIL 1999). Diante disso, durante a graduação em Ciências Biológicas tive ${ }^{3}$ a oportunidade de cursar disciplinas que abordam o histórico da Educação Ambiental, suas vertentes, desafios e potencialidades. Além dela, uma temática importante a ser trabalhada e investigada são os fungos, que até mesmo durante a jornada acadêmica são reduzidos em relação a sua potencialidade e importância.

Portanto, por meio das experiências adquiridas durante minha caminhada acadêmica, tornou-se significativo produzir uma pesquisa em formação continuada com professores, seguindo a proposta de uma Educação Ambiental "fora da caixa" articulando com a temática fungos, sendo esses seres vivos essenciais para o equilíbrio ambiental. Ademais, não somos as únicas a considerar que os fungos têm muito a nos ensinar. O famoso livro de Anna Tsing (2015), The mushroom at the end of the world, sugere o quanto outros seres vivos podem ser protagonistas do nosso aprendizado.

Segundo Martins e Oliveira (2015), a Educação Ambiental representa uma possibilidade de contribuir para a resolução de problemas ecossistêmicos, como por exemplo, as ameaças à biodiversidade. Wals et al. (1999) destacam a existência de várias estratégias que podem ser adotadas para que a conservação da biodiversidade seja considerada prioritária, como a construção de políticas públicas e práticas educativas em ambientes formais e não-formais, sendo assim, cruciais para a construção de valores e transformação da realidade socioambiental (MARTINS; OLIVEIRA, 2015).

De acordo com Oliveira et al. (2016), ao investigar a Educação Ambiental voltada para a biodiversidade, vários estudos têm feito essa interface entre as áreas de pesquisa, como é o caso do trabalho de Martins e Oliveira (2015), que produziram uma pesquisa com objetivo de analisar as concepções que professores e alunos do Ensino Fundamental II possuem acerca do termo biodiversidade. Além deste, o Projeto UÇÁ, é projeto que busca realizar esta interface, ele envolve a elaboração de atividades em Educação Ambiental (cadernos de pintura, catálogos, propostas de atividades em Educação Ambiental, artigos científicos etc.), atingindo toda a comunidade e enfatizando a importância da conservação da biodiversidade (PROJETO UÇÁ, 2012).

Um grupo de seres vivos que por vezes passam despercebidos, são os fungos. Por este motivo, é importante ressignificar o olhar para tais seres por meio de uma Educação Ambiental "fora da caixa" (CARVALHO; MHULE, 2016),

\footnotetext{
${ }^{3}$ A redação em primeira pessoa do singular é um compromisso ontológico com a experiência vivenciada pela primeira autora desse artigo. Por vezes, usaremos a primeira pessoa do plural já que a segunda autora também acompanhou essa vivência.
}

revista brasileira educação ambiental 
a qual tem a potencialidade de promover a atenção plena e a abertura para a experiência seguindo a perspectiva de educação da atenção proposta por Tim Ingold (2010). A educação da atenção é um refinamento do sistema perceptivo, na qual, o tutor media um processo que orienta a atenção do iniciante:

O processo de aprendizado por redescobrimento dirigido é transmitido mais corretamente pela noção de mostrar. Mostrar alguma coisa a alguém é fazer esta coisa se tornar presente para esta pessoa, de modo que ela possa apreendê-la diretamente, seja olhando, ouvindo ou sentindo. Aqui, o papel do tutor é criar situações nas quais o iniciante é instruído a cuidar especialmente deste ou daquele aspecto do que pode ser visto, tocado ou ouvido, para poder assim 'pegar o jeito' da coisa [...]. Aprender, neste sentido, é equivalente a uma 'educação da atenção' (INGOLD, 2010, p. 21).

No que diz respeito a formação continuada de professores frente à temática fungos, nenhum trabalho publicado foi encontrado, o que reforça a importância em realizar pesquisas nesta área. Além disso, a relação entre os fungos e a Educação Ambiental se faz pertinente entre os estudos, exibindo a necessidade e importância de ambos, mas principalmente, buscar compreender como as futuras gerações estão sendo preparadas dentro dessa temática. Portanto, o objetivo deste estudo é relatar o desenvolvimento e análise de um curso online sobre fungos para professores da Educação Básica de Palotina (PR) sob a perspectiva da Educação Ambiental "fora da caixa".

\section{Educação Ambiental e formação de professores}

De acordo com o artigo $1^{\circ}$ da Política Nacional de Educação Ambiental (BRASIL, 1999), entende-se por Educação Ambiental os processos pelos "quais o indivíduo e a coletividade constroem valores sociais, conhecimentos, habilidades, atitudes e competências" visando a conservação do meio ambiente, de uso comum da população, sendo essencial à boa qualidade de vida e sua sustentabilidade.

De acordo com Carvalho (2006), a Educação Ambiental como prática política e social é pautada em diferentes bases teóricas. Essa articulação dialética entre teoria e prática, constitui uma prática intencionalizada, a práxis, onde a educação cumpre sua perspectiva crítica e emancipadora. Diante disso, faz-se necessária implicar uma relação de reciprocidade das diferentes dimensões presentes na educação: a dimensão política da Educação Ambiental, do conhecimento e dos valores éticos e estéticos.

Nosso manuscrito, possui foco na dimensão de valores éticos e estéticos 
para a construção desse trabalho, sendo caracterizados pela ação corporal, onde 0 corpo e mente estão articulados para a estética sensorial e na autoformação criativa (SHUSTERMAN, 2011). Para Bauermann (2019) essa teoria pondera a remodelação da percepção e o papel do corpo nas experiências humanas.

O educador John Dewey (1859-1952), no século XX, revelou uma corrente de reforma escolar chamada de "escola ativa", contrapondo o método de escola tradicional. Esta escola tradicional determina o conhecimento como sendo unilateral, técnico e dicotômico, sem se importar com os valores, sentimentos e processos de aprendizado que cada indivíduo possui. O professor é o detentor do conhecimento e o repassa aos aprendizes. Para Pereira et al. (2009, p. 155), John Dewey "defendia que a educação deveria ser fonte de humanização e transformação social".

Payne e Wattchow (2009) produziram uma pesquisa de Educação Ambiental tendo como base a proposta de pedagogia ativa de John Dewey, e trabalharam a ideia de uma pedagogia lenta ou ecopedagogia, destacando a importância do corpo em uma educação com diversos ambientes. Essa ideia de ecopedagogia "atua como uma forma de desconstrução fenomenológica nas camadas pessoais, sociais, culturais e ecológica da experiência" (PAYNE; WATTCHOW, 2009, p.18, tradução nossa).

O trabalho desenvolvido por Carvalho e Mhule (2016) é condizente a ideia de Payne e Wattchow (2009), mas com viés em uma Educação Ambiental "fora da caixa", com propósito de elevar a experiência sensível, da criatividade e da criticidade, salientando que essa proposta reúne metodologias, ferramentas e ações para a Educação Ambiental de jovens e adultos fora dos modelos tradicionais impostos. Essa proposta de Educação Ambiental "fora da caixa" é baseada no conceito de educação da atenção, proposto por Tim Ingold (2010).

Ingold (2010, p.7) retrata a necessidade de "ir além da dicotomia, entre capacidades inatas e competências adquiridas", por meio de um "enfoque sobre as propriedades emergentes de sistemas dinâmicos". Ingold (2010) descreve que a educação da atenção é resultado de um processo de habilitação que cada geração alcança e ultrapassa, ou seja, o conhecimento humano, a contribuição que cada geração proporciona a seguinte, não são representações, mas sim uma educação da atenção. Em outras palavras, um indivíduo constrói conhecimentos com base na análise, na atenção do processo que outro indivíduo já experiente na área executa.

Outras pesquisas em Educação Ambiental têm se pautado nessa proposta, por exemplo Buss e lared (2020), que relatam uma experiência com Artrópodes durante as aulas de Artes. Para lared (2017, p.577), a abordagem da educação da atenção no âmbito da Educação Ambiental é importante por considerar o "engajamento sensorial que nos revela o mundo que é humano e abre formas éticas e afetivas de ser e estar no mundo". A educação da atenção e a Educação Ambiental "fora da caixa" convergem na preconização da 
experiência como um processo que revitaliza a criatividade, a reflexividade e a autonomia.

Pereira e Hamermuller (2017) produziram uma resenha da obra Pedagogias do século $X X I$ de Jaume Carbonell e, em consonância com o trabalho de Payne e Wattchow (2009) e a Educação Ambiental "fora da caixa" de Carvalho e Mhule (2016), defendem sobre uma pedagogia livre:

educação em liberdade; escolha do que se quer aprender; educação multidimensional para além da razão; ambientes, materiais e possibilidades diversificados; autogoverno/ constituição de uma microssociedade alternativa; o professor como facilitador; jornada de ensino flexível, sem horários e disciplinas (PEREIRA; HAMERMULLER, 2017, p.317).

No entanto, essas propostas pedagógicas "fora da caixa" têm dificuldade em adentrar a rigidez dos currículos escolares. Uhmann et al. (2017) revelam que a Educação Ambiental é importante na formação de todos os cidadãos e, por isso, a urgência em ampliar as discussões sobre meio ambiente nos espaços destinados a formação educacional. Porém, Thomaz (2006) relata que apesar da obrigatoriedade da Educação Ambiental em todas as modalidades de ensino, a sua prática e desenvolvimento no nível superior ainda permanece silenciada.

De fato, inúmeros estudos reconhecem a lacuna da formação inicial e continuada de professores em Educação Ambiental (MOTA, 2017). Diante disso, Buczenko e Rosa (2018) retratam que, mesmo com o empenho por políticas públicas para a Educação Ambiental, a realidade dos professores com relação a formação continuada ainda é precária, mesmo com os avanços obtidos.

Além dessas dificuldades, autores como Barbosa e Oliveira (2020), Andrade e Piccinini (2017) e Behrend, Cousin e Galiazzi (2018) perceberam a falta do termo Educação Ambiental no documento normativo da Base Nacional Comum Curricular (BNCC), levando em conta que este novo documento é considerado um retrocesso à implementação da Educação Ambiental nas escolas, infringindo políticas públicas. Behrend, Cousin e Galiazzi (2018) analisaram que o contexto da Educação Ambiental foi abordado com conteúdos conservacionistas e naturalistas, excluindo a problematização da Educação Ambiental segundo os aspectos éticos, políticos, econômicos e sociais. $O$ documento direciona o processo de aprendizagem para o mercado de trabalho, além de minimizar a autonomia das escolas e consequentemente dos professores (BEHREND; COUSIN; GALIAZZI, 2018). 


\section{Os fungos}

De acordo com o princípio 16 do Tratado de Educação Ambiental (RIO DE JANEIRO, 1992), é dever da Educação Ambiental "ajudar a desenvolver uma consciência ética sobre todas as formas de vida com as quais compartilhamos este planeta, respeitar seus ciclos vitais e impor limites à exploração dessas formas de vida pelos seres humanos". Assim sendo, considera-se necessário articular os fungos com a Educação Ambiental, de modo a vivenciar toda sua importância.

Os fungos fazem parte de uma grande e diversa linhagem de organismos pertencentes ao Domínio Eukarya (CAVALIER-SMITH, 1998) e ao Reino Fungi, sendo seres eucariontes que supostamente evoluíram de um ancestral protista unicelular que possuía um flagelo (SADAVA et al., 2009). Estes seres habitam os mais variados locais do planeta, mas ainda assim são pouco conhecidos, principalmente pela sua importância nos ecossistemas (CORTEZ; FERREIRA, 2015). Os fungos podem ser unicelulares, no caso das leveduras, ou multicelulares, como os cogumelos, variando imensamente em termos de estrutura corporal (ADAMS, 2004).

Segundo Abreu, Rovida e Pamphile (2015) e Moreira e Siqueira (2006) os fungos são excepcionalmente necessários para os ecossistemas, auxiliando na produção de alimentos (produtos fermentados e bebidas alcóolicas), produtos agrícolas (cogumelos comestíveis e microproteínas) ou patógenos de plantas cultivadas, na indústria farmacêutica, no processo de biodegradação e tratamento biológico de efluentes. Além disso, os fungos mantêm o equilíbrio do ambiente, decompondo restos vegetais, degradando substâncias nocivas (defensivos agrícolas, metais pesados e radioativos) com potencial para atuarem como agentes de controle biológicos, formando simbioses mutualísticas com plantas (micorrizas) e algas verdes ou cianobactérias formando liquens (ABREU; ROVIDA; PAMPHILE, 2015; MOREIRA; SIQUEIRA, 2006).

Bactérias e fungos são considerados como os principais decompositores da biosfera (GRANDI, 2007). Além disso, o processo de degradação de matéria libera gás carbônico na atmosfera e faz com que compostos nitrogenados e outras substâncias retornem ao solo, para que plantas e animais possam reutilizá-los, continuando o ciclo vital da biosfera (ZAPPE; SAUERWEIN, 2018).

Moreira e Siqueira (2006) e Brahmaprakash e Sahu (2012) evidenciam que a relação simbiótica entre plantas e fungos aumenta a capacidade de absorção de nutrientes, promovendo inúmeros benefícios mútuos. Os estudos envolvendo as micorrizas visam aumentar a produção de alimentos e diminuir o uso de fertilizantes químicos, contribuindo para uma agricultura mais sustentável (MOREIRA; SIQUEIRA, 2006).

As micorrizas também atuam como atenuadoras da fitotoxidez causada pelos metais (LEYVAL; TURNAU; HASELWANDTER, 1997). Plantas micorrizadas podem apresentar intensa tolerância a diferentes metais, 
compensando ao fungo simbionte vantagens na sobrevivência em local contaminado. Contudo, ainda não é possível recuperar completamente áreas degradadas por agentes químicos, porém, há estudos promissores pelo uso biológico de plantas e microrganismos, como o caso das micorrizas (SIQUEIRA; POUYÚ; MOREIRA, 1999).

Para Moreira e Siqueira (2006), as atividades simbióticas de líquens capturam a energia luminosa e, no caso de cianobactérias, fixam nitrogênio atmosférico. Os fungos absorvem nutrientes minerais e auxiliam na regulação da água e, além disso, essa simbiose permite a sobrevivência de ambos os organismos não sendo possível a sobrevivência separada (MOREIRA; SIQUEIRA, 2006). Os líquens também são considerados como bioindicadores de poluição atmosférica (HONDA; VILEGAS, 1998). Segundo o relatório State of the World's Fungi, produzido por cientistas do Kew Botanical Gardens da Inglaterra, os fungos possuem o potencial de quebrar resíduos de plásticos, sendo um avanço muito importante para as questões ambientais (CANNON et al., 2018).

Imersas nisso, é possível refletir que as ações dos fungos estão intimamente relacionadas à Educação Ambiental. Desde a decomposição de matéria orgânica, o uso na culinária, que busca uma alimentação mais saudável e sustentável, os estudos promissores a recuperação de solos contaminados e a degradação de plásticos, todos esses elementos se conectam com diversos aspectos de relevância na Educação Ambiental.

Embora muito relevantes, conforme os aspectos acima mencionados, os fungos ainda carecem de estudos e espaços, até mesmo no meio científico. Trata-se de uma área do conhecimento biológico em evidente expansão, mas que apresenta ainda alguns limitantes. Dentre os fatores que afetam os estudos de micologia, encontra-se a escassez de material bibliográfico disponível; falta de conhecimento sobre fungos no Brasil; o reduzido número de pesquisadores e especialistas na área, os fungos ainda serem figurados como "plantas inferiores" ou microrganismos; as dificuldades na terminologia e conceitos básicos que afastam o interesse dos estudantes ao tema; e a pouca ou nenhuma familiaridade da população com os fungos, geralmente correlacionados a malefícios.

\section{Metodologia}

A intervenção educativa, de caráter qualitativo (YIN, 2016), iniciou-se no ano de 2019 com uma reunião com a responsável pelos projetos de Ciências na Secretaria de Educação Municipal de Palotina (Paraná) a fim de apresentar o objetivo da pesquisa e a obter a permissão de aplicá-la. Para Yin (2016) é necessário a autorização por partes superiores no momento de realizar uma pesquisa qualitativa em ambientes formais públicos.

Com a aprovação do trabalho, foi desenvolvido um questionário 
diagnóstico e uma carta de apresentação para uma primeira aproximação com os professores da rede municipal e para o conhecimento prévio dos participantes a respeito dos fungos. Dentre várias técnicas de obtenção de dados, a aplicação do questionário foi selecionada, pois tem "o objetivo de conhecimento de opiniões, crenças, sentimentos, interesses, expectativas, situações vivenciadas" (GIL, 1999, p.128).

Posteriormente, em virtude da pandemia do novo coronavírus (Sars-CoV2), a pesquisa foi reestruturada para um curso online para professores da Educação Básica de Palotina/PR e região. Para tanto, foi utilizado um modelo de site denominado de WebQuest como meio de exposição de tarefas e materiais de apoio. De acordo com Pereira (2008), uma WebQuest é uma ferramenta metodológica de pesquisa na internet, voltada para o campo educacional, estimulando a pesquisa, o pensamento crítico, o desenvolvimento de docentes e produção de materiais. Além disso, possibilita a investigação de maneira organizada e orientada.

Para divulgar o curso, além do apoio da Secretaria Municipal de Educação de Palotina, foi produzido um panfleto virtual contendo informações gerais sobre o desenvolvimento do curso, e após as inscrições, os participantes receberam em seu e-mail o cronograma das atividades (Quadro 1), o qual foi elaborado de tal modo que, permite aos professores participantes, desenvolver as atividades práticas nos seus locais de convivência, como na escola, no quintal de casa, nas caminhadas pela cidade ou nas áreas verdes urbanas.

Quadro 1: Cronograma das Atividades

\begin{tabular}{|c|l|l|l|}
\hline DATA & \multicolumn{1}{|c|}{ ATIVIDADES } & COMO EXECUTAR? & \multicolumn{1}{c|}{ PRODUTO FINAL } \\
\hline $\begin{array}{c}\text { 12/06/2020 } \\
\text { De a } 60 \text { minutos }\end{array}$ & $\begin{array}{l}\text { Vídeo Conferência } \\
\text { Plataforma JitsiMeet }\end{array}$ & $\begin{array}{l}\text { Conversa com os } \\
\text { participantes do projeto }\end{array}$ & $\begin{array}{l}\text { Início do curso e explicação da } \\
\text { abordagem }\end{array}$ \\
\hline $\begin{array}{c}11 / 06 / 2020- \\
19 / 06 / 2020\end{array}$ & $\begin{array}{l}\text { Observação e coleta } \\
\text { de dados }\end{array}$ & $\begin{array}{l}\text { Instruções disponíveis } \\
\text { no site }\end{array}$ & $\begin{array}{l}\text { Fotografias e anotações sobre os } \\
\text { fungos encontrados }\end{array}$ \\
\hline $\begin{array}{c}19 / 06 / 2020- \\
29 / 06 / 2020\end{array}$ & $\begin{array}{l}\text { Produção de portfólio } \\
\text { digital }\end{array}$ & $\begin{array}{l}\text { Instruçães disponíveis } \\
\text { no site }\end{array}$ & $\begin{array}{l}\text { Produzir um portfólio digital } \\
\text { expondo as informações obtidas }\end{array}$ \\
\hline $\begin{array}{c}\text { De } 30 \text { a } 60 \text { minutos } \\
\text { Vídeo Conferência } \\
\text { Plataforma JitsiMeet }\end{array}$ & $\begin{array}{l}\text { Conversa entre os } \\
\text { participantes do projeto }\end{array}$ & Conclusão e avaliação do curso \\
$07 / 2020-16-$ & Avaliação do curso & Google Forms & Professores avaliam o curso \\
\hline & & & Emissão de certificados \\
\hline
\end{tabular}

Fonte: As autoras (2021)

Ao todo, obtivemos inscrições de 7 professores da educação básica, entretanto, apenas 5 desses concluíram o curso. Como produto final, os professores deveriam organizar um portfólio relatando os fungos encontrados no

Revbea, São Paulo, V.16, № 5: 500-520, 2021.

revista brasileira 
dia a dia, com o auxílio de roteiros disponibilizados, um para coleta de dados e outro para construção do portfólio, com informações que deveriam constar no trabalho: nome popular e/ou cientifico do fungo, onde se encontrava (troncos, solo com grama, etc.), percepção do local (se já o viu naquele ambiente outras vezes), a morfologia externa (descrição informal) e principalmente qual a importância observada daquele espécime para com aquele ambiente. Após esta coleta de dados, os professores deveriam montar um portfólio com tais informações.

Para produzir o portfólio, os professores utilizaram de registro fotográfico, o qual segundo Yin (2016), é uma ferramenta de obtenção de dados para pesquisa qualitativa e de fácil aplicação. $O$ registro fotográfico dos fungos foi proposto pensando na sensibilização e na educação da atenção para o grupo de seres vivos em questão, ou seja, uma atenção que permite um novo olhar aos fungos. De acordo com Zanellato (2008), geralmente os portfólios são apontados como técnicas para métodos avaliativos, porém, neste trabalho, os portfólios foram utilizados como instrumento de coleta de dados.

Para que os professores pudessem avaliar o curso, foi produzido um questionário avaliativo pelo Google Forms, com perguntas que buscassem a compreensão de como o curso tinha sido percebido pelos professores (qualidade e importância) e como poderia contribuir com a prática de Educação Ambiental junto aos alunos.

Portanto, configurou-se como corpus de análise do presente trabalho: o questionário diagnóstico, o portfólio e o questionário avaliativo. Para análise, optou-se pela triangulação dos dados, caracterizado por conferir significado a um fenômeno com base em diferentes técnicas de coleta de dados (DENZIN; LINCOLN, 2005).

\section{Resultados}

\section{Questionário Diagnóstico}

Apenas 03 professores responderam ao questionário diagnóstico e, pelo fato de ter sido preservado o anonimato dos respondentes, não é possível reconhecer se eles participaram do curso posteriormente. No Quadro 2, é possível visualizar as respostas dos professores com relação a estas questões em forma de palavras-chave. 
Quadro 2: Respostas do Questionário Diagnóstico

\begin{tabular}{|c|c|c|c|}
\hline QUESTÃO & PROFESSOR 'A' & PROFESSOR 'B' & PROFESSOR 'C' \\
\hline $\begin{array}{l}\text { No ambiente em que você } \\
\text { frequenta, já reparou na } \\
\text { presença de fungos? Como } \\
\text { eles são? }\end{array}$ & Micose, bolores. & Mofo, cogumelos. & $\begin{array}{l}\text { Saprófagos, liquens e } \\
\text { micorrizas. }\end{array}$ \\
\hline $\begin{array}{l}\text { Você compreende a relação } \\
\text { que os fungos possuem } \\
\text { com o meio ambiente? Se } \\
\text { sim, qual? }\end{array}$ & $\begin{array}{l}\text { Decompositores, } \\
\text { equilíbrio do } \\
\text { ecossistema. }\end{array}$ & Não. & Por todo ecossistema. \\
\hline $\begin{array}{l}\text { Você já abordou os fungos } \\
\text { em sala de aula? Se sim, } \\
\text { discorra um pouco sobre } \\
\text { essa experiência (pontos } \\
\text { fortes, dificuldades, quais } \\
\text { assuntos emergiram). Qual } \\
\text { a contribuição que os } \\
\text { estudantes trouxeram para } \\
\text { essa discussão sobre } \\
\text { fungos? }\end{array}$ & $\begin{array}{l}\text { Construção de um } \\
\text { observatório de de } \\
\text { fungos. }\end{array}$ & $\begin{array}{l}\text { Características } \\
\text { gerais do Reino } \\
\text { Fungi. }\end{array}$ & $\begin{array}{l}\text { Dificuldade em abordar } \\
\text { pela falta de } \\
\text { equipamentos } \\
\text { laboratoriais. }\end{array}$ \\
\hline $\begin{array}{l}\text { No seu entendimento, qual } \\
\text { o papel dos fungos no } \\
\text { contexto das Ciências e da } \\
\text { Biologia? }\end{array}$ & $\begin{array}{l}\text { Reciclagem } \\
\text { nutrientes } \\
\text { orgânicos. }\end{array}$ & $\begin{array}{l}\text { Reciclagem de } \\
\text { nutrientes } \\
\text { orgânicos; } \\
\text { decompositores. }\end{array}$ & $\begin{array}{l}\text { Relações } \\
\text { mutualísticas; } \\
\text { importância ecológica, } \\
\text { econômica e na } \\
\text { alimentação; } \\
\text { reciclagem de matéria } \\
\text { orgânica. }\end{array}$ \\
\hline
\end{tabular}

Fonte: As autoras (2021)

\section{Portfólios}

Os portfólios foram o produto final que os professores deveriam produzir, com base na observação e coleta de dados realizados a campo. Diante disso, foi proposto que os professores elaborassem os com base nos fungos encontrados.

Na Figura 1, 2, 3 e 4, apresenta-se uma página do portfólio de 4 participantes, nos quais é perceptível que o foco das descrições reside no aspecto científico, não sendo registrado os elementos somaestéticos da relação eu fungo ambiente. 


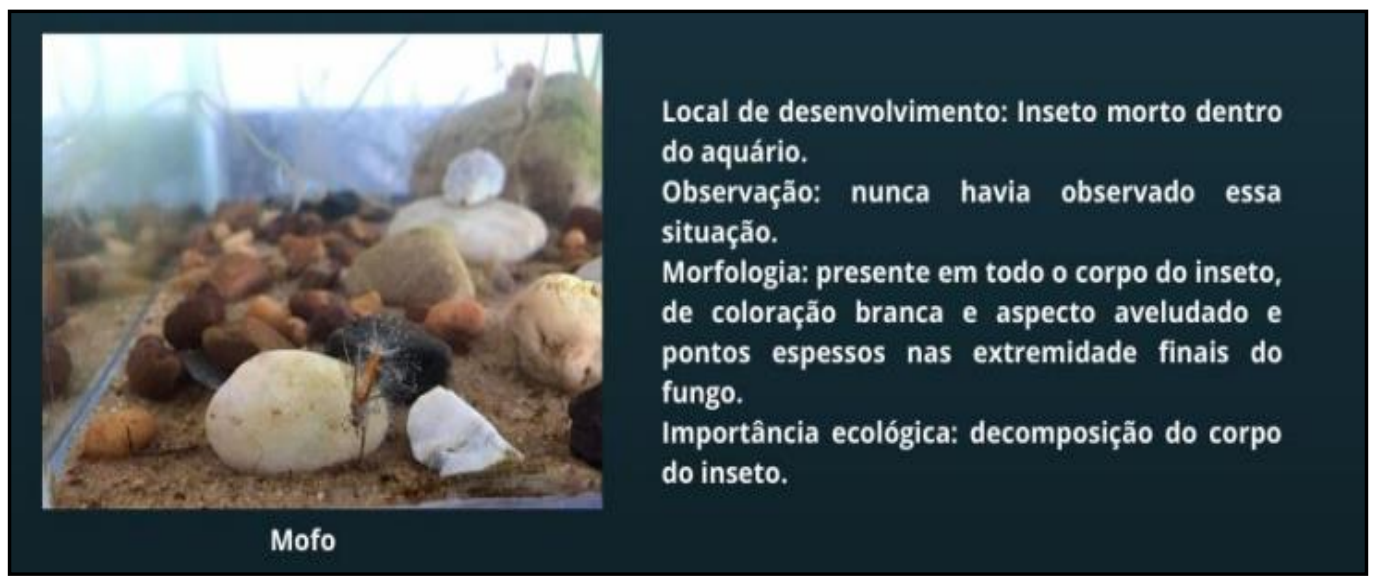

Figura 1: Página do portfólio P1. Fonte: P1 (2020).

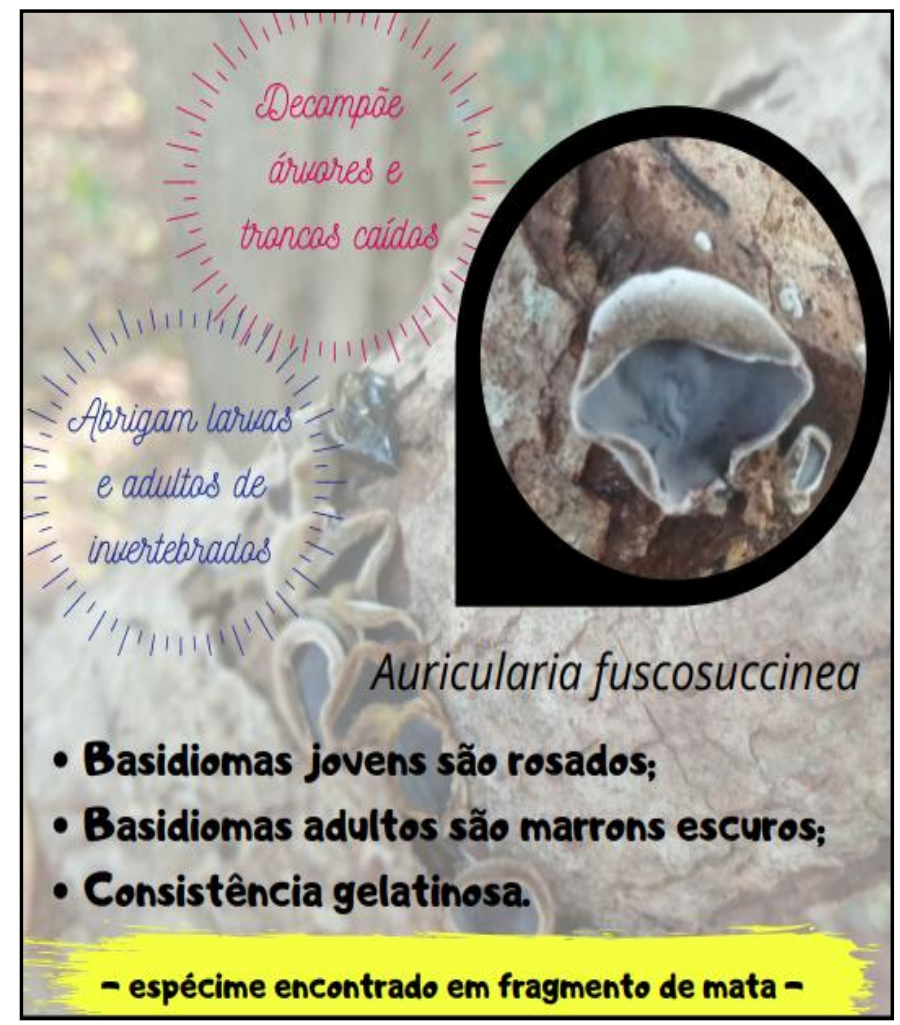

Figura 2: Página do portfólio P2.

Fonte: P2 (2020). 


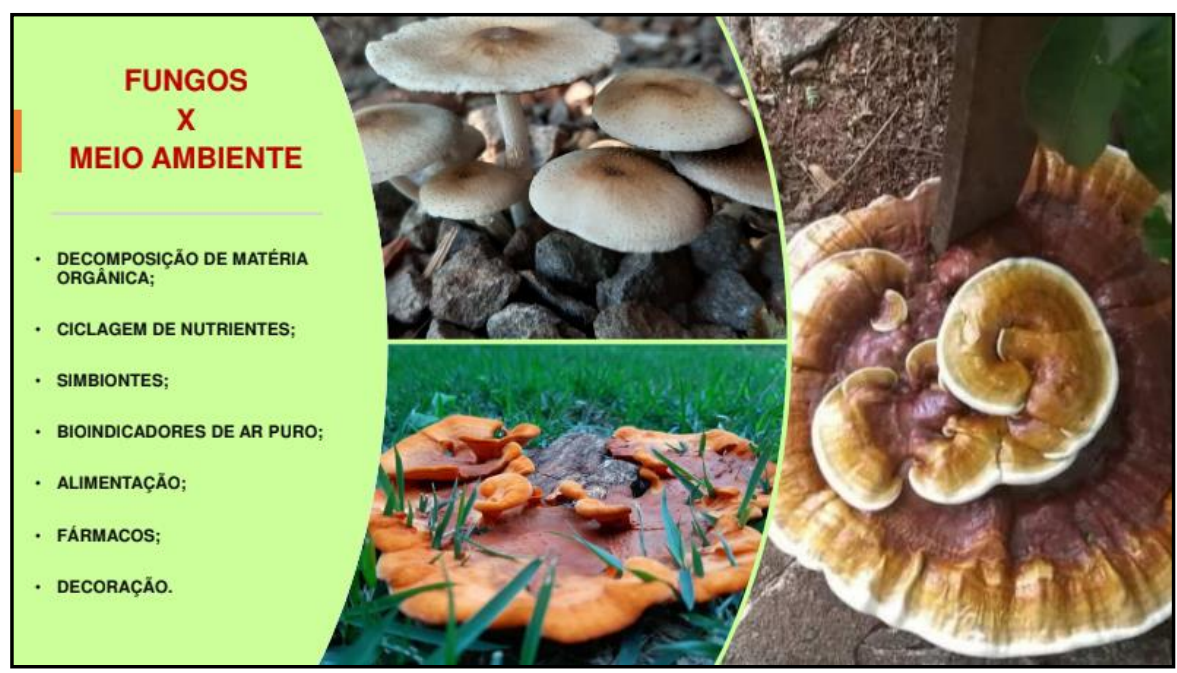

Figura 3: Página do portfólio P3.

Fonte: P3 (2020)

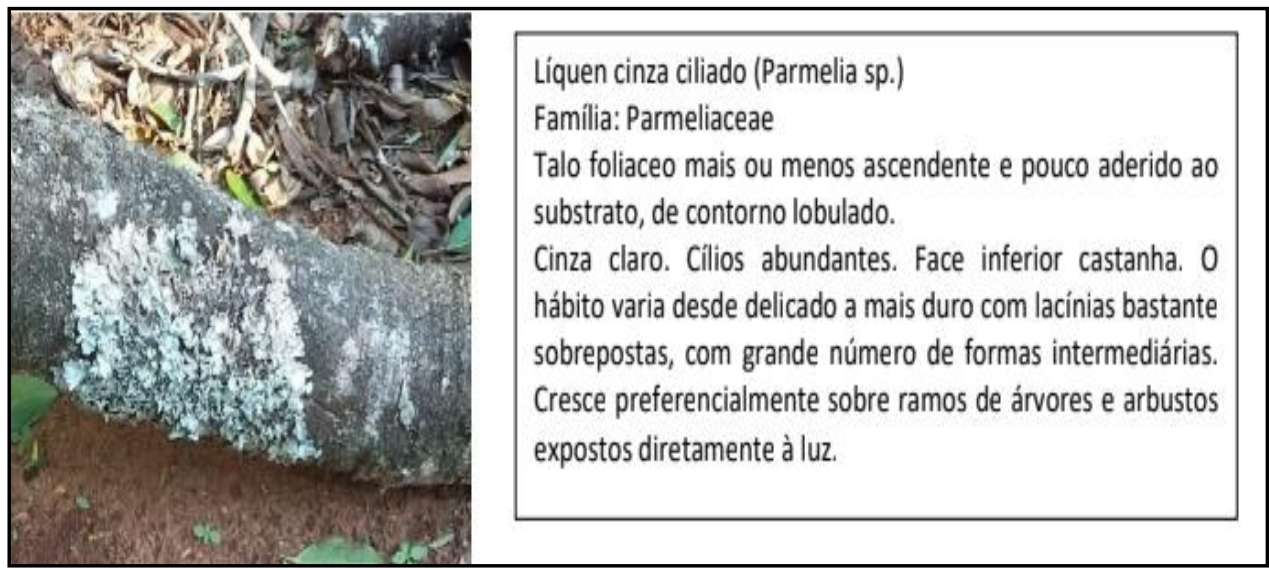

Figura 4: Página do portfólio P4.

Fonte: P4 (2020)

Contudo, entre os participantes se destacou o portfólio do P5 que conseguiu transcender a atividade para os aspectos somaestéticos, remetendo um olhar mais sensível e recorrendo a poesia, considerada um recurso didático fundamental para repensar nossa inter-relação com a natureza. Na Figura 5, é possível visualizar duas páginas do portfólio. 

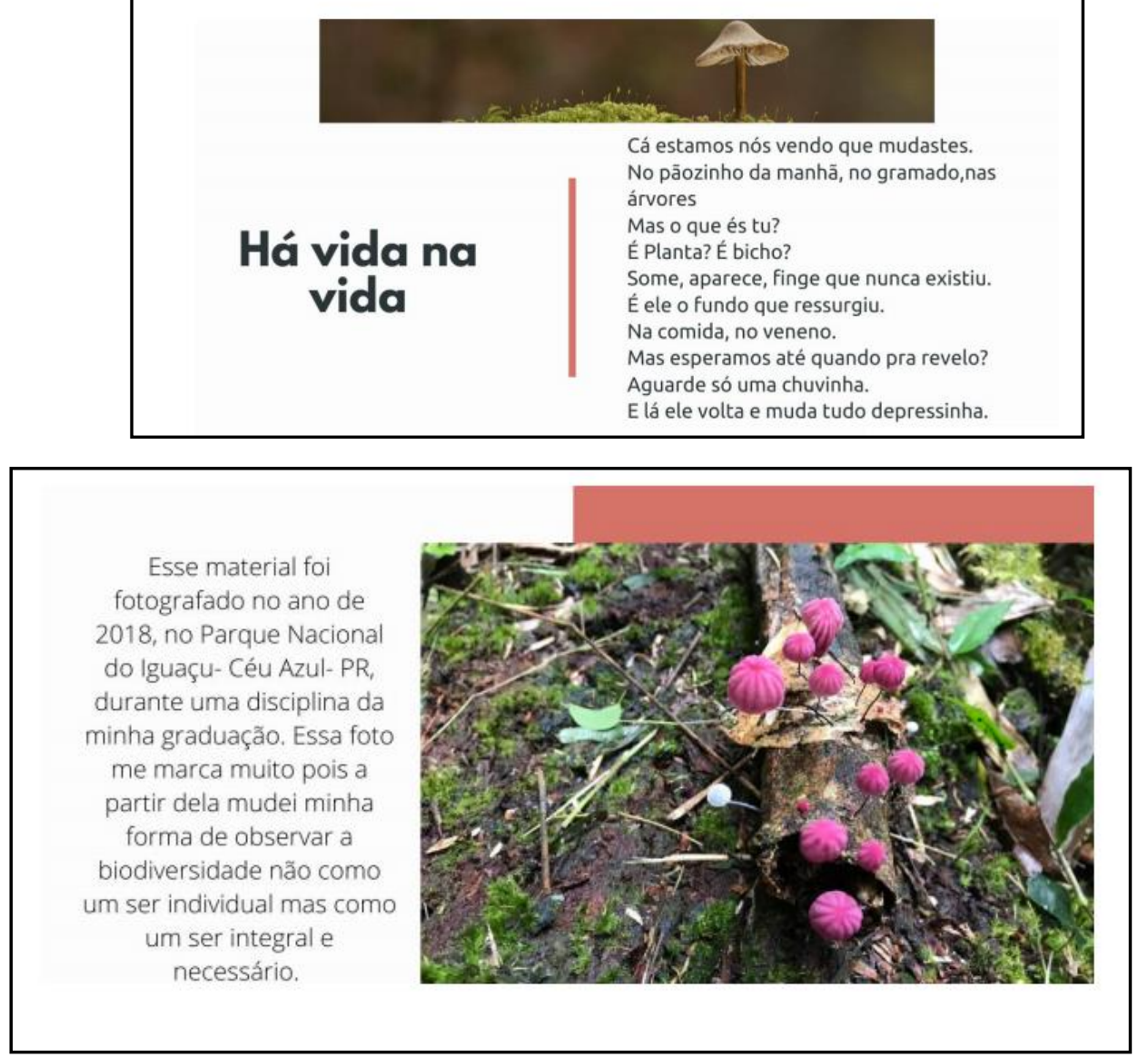

Figura 5: Portfólio do participante 5.

Fonte: P5 (2020)

Ao se fazer uma análise geral dos portfólios, identificamos a dificuldade em trabalhar com Educação Ambiental sendo predominante as características morfológicas e a importância ecológica. Essa dificuldade é relatada em vários outros trabalhos, como o de Carvalho e Mhule (2016), de Payne e Wattchow (2009) e de Payne (2005) sendo relacionada a nossa visão hegemônica e cartesiana, a qual valoriza o conhecimento científico em detrimento das outras dimensões da vida, como os valores éticos e estéticos.

\section{Questionário de Avaliação}

O questionário avaliativo foi aplicado ao final do curso e os participantes tiveram seu anonimato garantido. No Quadro 3, é possível verificar a avaliação dos professores, utilizando o uso de palavras-chave para a descrição. 
Quadro 3: Resultado do Questionário Avaliativo

\begin{tabular}{|c|c|}
\hline QUESTÃO & RESPOSTAS \\
\hline $\begin{array}{l}\text { De acordo com a sua participação no curso, como } \\
\text { você classificaria a assistência do mediador? }\end{array}$ & $\begin{array}{l}80 \% \text { - Ótimo } \\
20 \% \text { - Bom }\end{array}$ \\
\hline $\begin{array}{l}\text { Você acha que o tempo destinado as atividades foram } \\
\text { suficientes? }\end{array}$ & $100 \%-\operatorname{Sim}$ \\
\hline $\begin{array}{l}\text { Com relação ao site de apoio, como você o } \\
\text { classificaria? }\end{array}$ & $\begin{array}{l}80 \% \text { - Ótimo } \\
20 \% \text { - Bom }\end{array}$ \\
\hline $\begin{array}{l}\text { Para você, o curso contribuiu na sua formação pessoal } \\
\text { e profissional? }\end{array}$ & $100 \%-\operatorname{Sim}$ \\
\hline $\begin{array}{l}\text { Quais foram as principais dificuldades encontradas } \\
\text { durante o curso? }\end{array}$ & $\begin{array}{l}\text { Classificação taxonômica; coleta e } \\
\text { aplicativos digitais. }\end{array}$ \\
\hline Como este curso contribuiu para sua prática escolar? & $\begin{array}{l}\text { Novas metodologias } \\
\text { conhecimento. }\end{array}$ \\
\hline $\begin{array}{l}\text { Nos conte um pouco sobre a experiência adquirida } \\
\text { nesse curso! }\end{array}$ & $\begin{array}{l}\text { Visão abrangente e importância dos } \\
\text { fungos; } \\
\text { compartilhamento de experiências; } \\
\text { curiosidade. }\end{array}$ \\
\hline $\begin{array}{l}\text { Quais são suas contribuições para o curso? (Descreva } \\
\text { os pontos fortes e fracos, se houver, do curso no todo). }\end{array}$ & $\begin{array}{l}\text { Pontos fortes: ampliação do } \\
\text { trabalho no município; portfólio; } \\
\text { conhecimentos adquiridos. } \\
\text { Pontos fracos: esperava-se mais } \\
\text { encontros síncronos para trocas de } \\
\text { experiências; internet fraca. }\end{array}$ \\
\hline $\begin{array}{l}\text { No seu ponto de vista, os fungos e a Educação } \\
\text { Ambiental são temáticas importantes a serem } \\
\text { trabalhadas nas escolas? }\end{array}$ & Sim. \\
\hline $\begin{array}{l}\text { Com o curso, ficou claro a relação/importância dos } \\
\text { fungos e a Educação Ambiental? }\end{array}$ & $100 \%-\operatorname{Sim}$ \\
\hline No geral, como foi o curso? & $\begin{array}{l}60 \% \text { - Ótimo } \\
40 \%-\text { Bom }\end{array}$ \\
\hline
\end{tabular}

Fonte: As autoras (2020)

Ao adentrarmos nas questões que refletem sobre as percepções durante o curso, percebemos que a maioria das respostas está restrita ao conhecimento científico e poucas, reportam para uma perspectiva mais atencional do tema. É necessário enfatizar que o conhecimento científico é essencial e a proposta não é substitui-lo, mas acrescentar outras possibilidades da experiência somaestética. 


\section{Discussões}

Fragoso e Nascimento (2018) comentam que é perceptível que a prática ambiental faz parte de um pensamento complexo e inovador, é um conceito a se pensar e a ser inserido em nossas ações de ensino e de pesquisa. Da mesma maneira, Meira (2010) propõe que a transversalidade da temática meio ambiente tem o propósito de proporcionar uma visão ampla, não envolvendo somente os elementos naturais, mas também os elementos formados e todos os aspectos sociais envolvidos na questão ambiental.

A proposta de uma Educação Ambiental "fora da caixa" (CARVALHO; MHULE, 2016) objetivou permitir que os professores buscassem um novo olhar para o ambiente que o circunda, ou seja, sensibilizar-se pela biodiversidade oculta (THIEMANN; OLIVEIRA, 2013). Diante disso, ao realizar a triangulação de dados um aspecto em comum destaca para todos os elementos: uma educação pautada em uma lógica cartesiana se sobressaiu. Parafraseando, nossos dados apontaram para uma Educação Ambiental que continua "dentro da caixa".

Analisando o questionário diagnóstico e o avaliativo, é perceptível que os professores estavam envolvidos e interessados no trabalho. Entretanto, apresentam uma visão cartesiana, não refletindo uma Educação Ambiental que ultrapassasse os aspectos ecológicos e biológicos. Segundo Lima (1999, p.144) essa visão técnica de ensino, "além de simplificador é deformador, reduz a complexa multidimensionalidade da temática ambiental à unidimensionalidade técnica". Semelhante a isso, aborda que a tendência de reduzir a questão ambiental a um problema ecológico é limitante e de certa forma enganadora, pois retira da questão ambiental uma de suas características primordiais que é "unir realidades, articular e relacionar dimensões complementares que constituem uma complexidade maior". Ainda complementa com Morin (1977) ao afirmar que esse potencial de articulação pondera a perder a visão sistêmica da realidade que se entende a vida e a questão ambiental como um meio de relações, integrado, onde todos se comunicam entre si e com a totalidade (LIMA, 1999).

Ingold (2010) aborda que a educação da atenção tem o propósito de provocar uma sensibilização humana para os detalhes cotidianos em contraposição a um modelo de ciência objetiva que propõe uma relação de sujeito (pesquisador) e objeto (natureza). Apenas um participante conseguiu trazer os elementos somaestéticos entre 0 eu fungos ambiente ${ }^{4}$ para 0 portfólio, o que aponta para uma multissensorialidade da experiência dele/a com o fungo.

Trabalhar com a educação "fora da caixa" exige desafios, que ficaram nítidos neste trabalho, pois mesmo com o engajamento de todos os

4 O til ( ) é proposital, evidenciando a indissociação entre os elementos, de estarem emaranhados.

Revbea, São Paulo, V.16, № 5: 500-520, 2021. 
participantes, os dados apontaram a dificuldade em se trabalhar com uma Educação Ambiental sensível, que era o propósito do curso. Outros trabalhos como o já citado de Carvalho e Mhule (2016), Payne (2005) e Charlot (2020) identificaram o mesmo desafio, pelo fato de que o ensino cartesiano ainda está presente no âmbito educacional.

Payne (2005) realizou um estudo comparando o aprendizado via método cartesiano e via as sensibilidades artísticas. O autor conclui que os métodos de investigação da experiência humana são menos satisfatórios para a percepção e vivência do ambiente, pois, os aprendizes estão mais envolvidos com a construção e explicação de relações e entendimentos positivistas entre o ser humano e o meio ambiente e isso provoca o rebaixamento da sensibilidade e do potencial do somaestético (PAYNE, 2005).

Charlot (2020) fez um resgate histórico das pedagogias que passaram pela educação e sugere que a educação ainda enfatiza um ensino tradicionalista, reducionista e unilateral. Para Charlot (2020), isso também se reflete nas práticas em Educação Ambiental, onde os trabalhos são realizados, por vezes, de modo competitivo, sem se importar com a sensibilidade necessária para com o meio que o ser humano habita. Diante disso, o autor comenta sobre a implementação de uma pedagogia contemporânea, sendo uma teoria que privilegia a formação do ser humano, seus conhecimentos, suas formas de agir, de pensar, suas culturas e seu processo crítico. Charlot (2020, p.19) ainda afirma que "não se trata de pensar em uma Educação Ambiental, mas o componente ambiental de um projeto antropo-pedagógico contemporâneo".

O processo de trabalhar com a educação da atenção (INGOLD, 2010) e educação "fora da caixa" (CARVALHO; MHULE, 2016) é desafiador, pois visa provocar pedagogias mais atencionais ao invés das intencionais. Muitos estudos $^{5}$ defendem a necessidade da implantação desta perspectiva, valorizando os sentimentos, a experiência, capacidades reflexivas e a criatividade, permitindo que o pesquisador busque conhecimentos além do modo tradicionalista, unilateral e tecnicista. De acordo com Carvalho e Mhule (2016, p. 36), Ingold descreve que "uma pessoa não aprende e apreende as coisas da vida simplesmente por sua capacidade e competência cognitiva, mas sim através de um processo complexo do indivíduo imerso no ambiente num continuum que o permite adquirir e desenvolver habilidades".

\section{Considerações Finais}

Por meio deste relato de experiência, notamos que os desafios encontrados nesse trabalho são congruentes com outros que buscam 0 engajamento corporal do sujeito no mundo. Ademais, devido a escassa literatura que aborde a relação dos fungos com a Educação Ambiental, os mesmos devem

\footnotetext{
${ }^{5}$ Aqui sugerimos o documentário: O começo da via 2 - Lá fora. Direção de Renata Terra. São Paulo: Maria farinha filmes, 2020. Meio digital (90 minutos).
} 
ser motivados como tema gerador, sendo significativos para uma perspectiva que busca despertar a sensibilidade, a experiência, a criatividade e a criticidade na educação por meio da biodiversidade local. Os trabalhos de Ingold (2010) e Carvalho e Mhule (2016) foram a base para a realização deste estudo, mostrando o quanto estas práticas são importantes e a necessidade de serem inseridas na educação, em espaços formais e não formais.

Os recursos tecnológicos utilizados para esta pesquisa tiveram uma contribuição importante, pois a internet e seus meios permitiram a realização deste trabalho em meio à pandemia do Sars-CoV-2. O uso de portfólios se configurou em uma opção significativa para a prática em educação da atenção, pois é um material que permite a emersão da criatividade e imaginação.

\section{Agradecimentos}

Agradecemos a Secretaria Municipal de Educação de Palotina (Paraná) e aos professores participantes do projeto.

\section{Referências}

ABREU, J. A. S.; ROVIDA, A. F. S.; PAMPHILE, J. A. Fungos de interesse: aplicações biotecnológicas. Revista Uningá. v. 21, n. 1, p. 55-59, 2015.

ADAMS, D. J. Fungal cell wall chitinases and glucanases. Microbioly. v.150, p. 2029-2035, 2004.

ANDRADE, M.C.P.; PICCININI, C.L. Educação Ambiental na Base Nacional Comum Curricular: retrocessos e contradições e o apagamento do debate socioambiental. In: ENCONTRO PESQUISA EM EDUCAÇÃO AMBIENTAL, 9., 2017, Juiz de Fora. Anais... . Juiz de Fora: UFJF, UFF e FFCLRP/USP, 2017. p. 1 - 13. Disponível em: <http://www.colemarx.com.br/wpcontent/uploads/2018/03/EDUCA\%C3\%87\%C3\%830-AMBIENTAL-NA-BASENACIONAL-COMUM-CURRICULARRETROCESSOS CONTRADI\%C3\%87\%C3\%95ES-E-O-APAGAMENTO-DODEBATE-SOCIOAMBIENTAL.pdf >. Acesso em: 15 abr 2020.

BARBOSA, G. S.; OLIVEIRA, C. T. Educação Ambiental na Base Nacional Comum Curricular. Revista Eletrônica do Mestrado em Educação Ambiental. Rio Grande: v. 37, n. 1. p.323-335, 2020.

BAUERMANN, L. Os princípios da somaestética como proposta para pensar em práticas educativas em dança. Anais... Editora PUCRS: Filosofia da Educação, 2019.

BEHREND, D. M.; COUSIN, C. S.; GALIAZZI, M. do C. Base Nacional Comum Curricular: $O$ que se mostra de referência à Educação Ambiental?. Ambiente e Educação: Revista de Educação Ambiental, Porto Alegre, v. 23, n. 2, p. 7489, 2018. 
BRAHMAPRAKASH, G. P.; SAHU, P. K. Biofertilizers for sustainability. Journal of the Indian Institute of Science. v. 92, n. 1, p. 37-62, 2012.

BRASIL. Constituição da República Federativa do Brasil. Artigo no 225, de 1988. Brasília - DF, $1988 . \quad$ Disponível: < http://www.planalto.gov.br/ccivil 03/constituicao/constituicao.htm >. Acesso em: 25 fev. 2020.

BRASIL. Política Nacional de Educação Ambiental, Lei 9795. Diário Oficial da República Federativa do Brasil, Brasília, DF, 27 abr. 1999. Disponível em: $<$ http://www.planalto.gov.br/ccivil 03/Leis/L9795.htm> Acesso em: 25 fev. 2020.

BUCZENKO, G. L.; ROSA, M. A. Educação Ambiental e a formação de pedagogos. Cadernos de Pesquisa: Pensamento Educacional. Curitiba: p. 4766, 2018.

BUSS, B, C.; IARED, V. G. Artrópodes como tema gerador de uma prática educativa em uma escola de artes no município de Palotina (PR). Revista Brasileira de Educação Ambiental, v. 15, n. 1, p. 379-396, 2020.

CANNON, P. F. et al. Kew Botanical Gardens. State of the World's Fungi. Alemanha, 2018. Relatório oficial.

CARVALHO, I. C. M.; MHULE, R. P. Intenção e Atenção nos processos de Aprendizagem: por uma Educação Ambiental "Fora da Caixa". Ambiente e Educação, v. 21, n. 1, p. 26-40, 2016.

CARVALHO, L. M. A temática ambiental e o processo educativo: dimensões e abordagens. In: CINQUETTI, H.C.S.; LOGAREZZI, A. (org.). Consumo e resíduo: fundamentos para o trabalho educativo. São Carlos: EDUFSCAR, 2006. p. 19-41.

CAVALIER-SMITH, T. A revised six-kingdom system of life. Biology Review Cambrige, Philological Society, v.73, p. 203-266, 1998.

CORTEZ, V. G.; FERREIRA, A. J. Macrofungos de Palotina. In: CORTEZ, V. G.; GONÇALVES, R. B. (orgs). Guia da Biodiversidade de Palotina. Palotina: UFPR, 2015. p. 19-46.

DENZIN, N. K.; LINCOLN, Y. S. Introduction: The discipline and practice of qualitative research. In: DENZIN, N. K.; LINCOLN, Y. S. (Eds.). The Sage Handbook of qualitative research. 4. Ed. Thousand Oaks: Sage, 2005. P. 1 32.

BUCZENKO, G. L.; ROSA, M. A. Educação Ambiental e a formação de pedagogos. Cadernos de Pesquisa: Pensamento Educacional. Curitiba: $p$. 47-66, 2018.

BUSS, B, C.; IARED, V. G. Artrópodes como tema gerador de uma prática educativa em uma escola de artes no município de Palotina (PR). Revista Brasileira de Educação Ambiental, v. 15, n. 1, p. 379-396, 2020. 
CANNON, P. F. et al. Kew Botanical Gardens. State of the World's Fungi. Alemanha, 2018. Relatório oficial.

CARVALHO, I. C. M.; MHULE, R. P. Intenção e Atenção nos processos de Aprendizagem: por uma Educação Ambiental "Fora da Caixa". Ambiente e Educação. v. 21, n. 1, p. 26-40, 2016.

CARVALHO, L. M. A temática ambiental e o processo educativo: dimensões e abordagens. In: CINQUETTI, H.C.S.; LOGAREZZI, A. (org.). Consumo e resíduo: fundamentos para o trabalho educativo. São Carlos: EDUFSCAR, 2006. p. 19-41.

CAVALIER-SMITH, T. A revised six-kingdom system of life. Biology Review Cambrige, Philological Society, v.73, p. 203-266, 1998.

FRAGOSO, E.; NASCIMENTO, E. C. M. A Educação Ambiental no ensino e na prática escolar da escola Estadual Cândido Mariano - Aquidauana/MS. Revista de Educação Ambiental, v. 23, n. 1, p. 161-184, 2018.

GIL, A.C. Métodos e técnicas de pesquisa social. 5.Ed. São Paulo: Atlas, 1999.

GRANDI, R. A. P. Fungos. In: RAVEN, Peter H.; EVERT, Ray F.; EICHHORN, Susan E. Biologia Vegetal. 7. Ed. Rio de Janeiro: Guanabara Koogan S.A, 2007.

HONDA, N. K.; VILEGAS, W. A química dos líquens. Química Nova. v. 21, n. 6, p. 110-125, 1998.

IARED, V. G. A ecomotricidade na Educação Ambiental. In: Colóquio de Pesquisa Qualitativa em Motricidade Humana: Ecomotricidade e Bem Viver, 7., 2017, Aracaju; São Cristóvão. Anais... São Carlos: SPQMH, 2017, p. 570-580.

INGOLD, T. Da transmissão de representações à educação da atenção. Educação. Porto Alegre: v. 33, n. 1, p. 6-25, 2010.

LEYVAL, C.; TURNAU, K.; HASELWANDTER, K. Effect of heavy metal pollution on mycorrhizal colonization and function: physiological, ecological and applied aspects. Mycorrhiza., n. 7, p. 139-153, 1997.

LIMA, G. C. Questão ambiental e educação: contribuições para o debate. Ambiente e Sociedade, v. 2, n. 5, p. 135-153, 1999.

MARTINS, C.; OLIVEIRA, H. T. Biodiversidade no contexto escolar: concepções e práticas em uma perspectiva de Educação Ambiental crítica. Revista Brasileira de Educação Ambiental. São Paulo: v. 10, n. 1, p. 127-145, 2015.

MEIRA, Z. A. A contribuição do Curso de Letras para a Educação Ambiental. Especialização em Docência para o Magistério em Itaituba, PA. Graduada em Letras. Disponível em <http://www.webartigos.com/artigos/acontribuicao-docurso-de-letras-para-a-educacao-ambiental/45155/>. Acesso em: 16 jul 2020.

MOREIRA, F. M. S.; SIQUEIRA, J. O. Microbiologia e Bioquímica do solo. 2.ed. Lavras: Editora UFLA, 2006. 
MOTA, J. C. Formações continuadas em Educação Ambiental: características e limitações. Revista Espaço Acadêmico, n. 192, p. 59-68, 2017.

OLIVEIRA, H. T. et al. Educação Ambiental para a conservação da biodiversidade: animais de topo de cadeia. São Carlos: Diagrama Editorial, 2016.

PROJETO UÇÁ. Programa Petrobrás Socioambiental. Guanabara, 2012. Disponível em: < http://projetouca.org.br/o-projeto/ >. Acesso em: 15 abr 2020.

PAYNE, P. "Ways of Doing," Learning, Teaching, and Researching. Canadian Journal of Environmental Education, Australia: v. 10, p. 108-124, 2005.

PAYNE, P. G.; WATTCHOW, B. Phenomenological Deconstruction, Slow Pedagogy, and the Corporeal Turn in Wild Environmental/Outdoor Education. Canadian Journal of Environmental Education, Melbourne: v. 14, p. 15-32, 2009.

PEREIRA, E. A. et al. A contribuição de John Dewey para a educação. Revista Eletrônica de Educação, v. 3, n. 1, p. 154 -161, 2009.

PEREIRA, J. G. L. T.; HAMERMULLER, D. O. Pedagogias do século XXI. CARBONELL, J. Pedagogias do século XXI. 3. ed. Porto Alegre: Penso, 2016. 263 p. Educar em Revista, Curitiba: n. 63, p. 315-319, 2017. Resenha.

PEREIRA, R. W. WebQuest: ferramenta pedagógica para o professor. Secretaria do Estado de Educação, 68p, 2008.

RIO DE JANEIRO. Tratado de Educação Ambiental para Sociedades Sustentáveis e Responsabilidade Global. Rio de Janeiro, Brasil, 1992. Disponível em http://portal.mec.gov.br/secad/arquivos/pdf/educacaoambiental/tratado.pdf $>$. Acesso em 25 mai 2020.

SADAVA, D. et al. Vida: a ciência da biologia. Evolução, Diversidade e Ecologia. Porto Alegre: Artmed, 2009.

SHUSTERMAN, R. Pensar Através do Corpo, Educar para as Humanidades: Um Apelo para a Soma-Estética. Philia\&Filia, Porto Alegre: v. 02, n. 2, p. 6-33, 2011.

SIQUEIRA, J. O.; POUYÚ, E.; MOREIRA, F. M. S. Micorrizas arbusculares no crescimento pós-transplantio de mudas de árvores em solo com excesso de metais pesados. Revista Brasileira de Ciência do Solo, v. 23, p. 569-580, 1999.

THIEMANN, F. T.; OLIVEIRA, H. T. Biodiversidade: sentidos atribuídos e as contribuições do tema para uma Educação Ambiental Crítica. Pesquisa em Educação Ambiental, v. 8, n. 1, p. 114-128, 2013.

THOMAZ, C. E. Educação Ambiental na formação inicial de professores.108 f. Dissertação (Mestrado em Educação) - Centro de Ciências Sociais Aplicadas, Pontíficia Universidade Católica de Campinas, Campinas, 2006. 
TSING, A. L. The mushroom at the end of the world: On the possibility of life in capitalist ruins. Princeton University Press, 2015.

UHMANN, R. I. M. et al. Contextualização da Educação Ambiental do ensino de Ciências e Química. Anais... Rodas de Formação de Professores na Educação Química. Universidade Federal do Rio Grande, EDEC/FURG, 2017.

YIN, R. K. Pesquisa qualitativa do início ao fim. Porto Alegre: Penso, 2016.

ZANELLATO, J. R. O portfólio como instrumento de avaliação no ensino de graduação em Artes Visuais. 124f. Dissertação (Mestrado). Curso de PósGraduação em Educação. Pontifícia Universidade Católica de Campinas, Campinas, 2008.

ZAPPE, J. A.; SAUERWEIN, I. P. S. Os pressupostos da educação pela pesquisa e o ensino de fungos: o relato de uma experiência didática. Revista Electrónica de Enseñanza de las Ciencias. v. 17, n. 2, p. 476-490, 2018. 